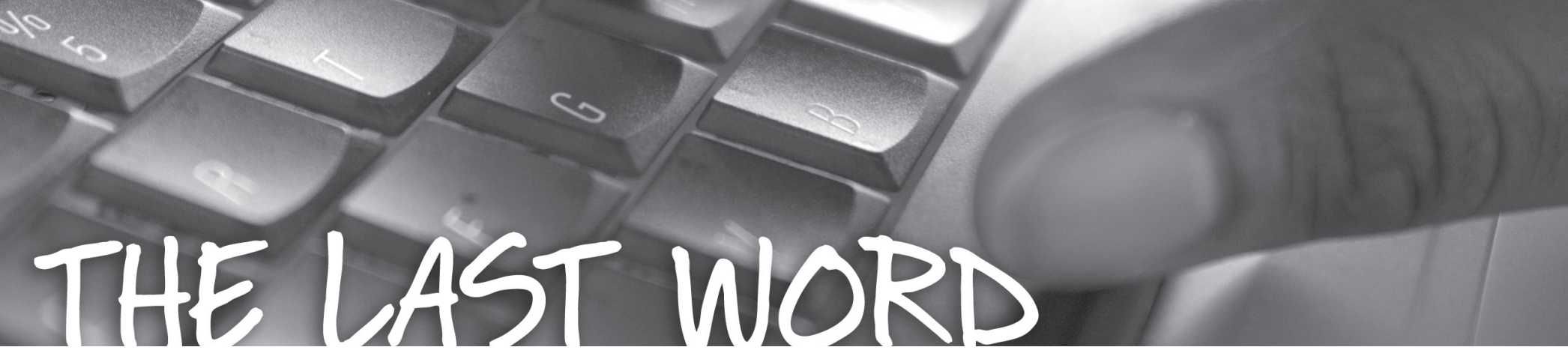

\title{
The Colors of Duckie's Rainbow
}

\section{BY AMANDA SPINO}

As I prepare for my first preschool storytime as a youth services librarian, I couldn't be more excited. After much pondering, I decide that "ducks" was a fitting theme. I choose the books, memorize the songs and rhymes, and prepare a flannel board. Finally, I am ready. My first storytime is sure to be a success.

In rushes a group of lively preschoolers, taking their seats and staring at me expectantly.

"Hello!" I exclaim enthusiastically. "My name is Miss Amanda. How is everyone today?"

Silence. The children stare at me for so long that I wonder if there is ink on my face. With a weak smile, I continue.

"Our first book is Duckie's Rainbow. I need your help naming the colors." I turn to the first page and point to the red poppy field.

For a moment it is quiet. Then one brave little girl speaks up. "Rojo."

"Err... yes," I respond, trying to recall my high school Spanish. "Let's try another page."

"Anaranjado!" shouts a boy as I turn to a page with an orange bridge.
This first program taught me a valuable lesson-I had to find a way to connect with my patrons and meet their needs, not the other way around.

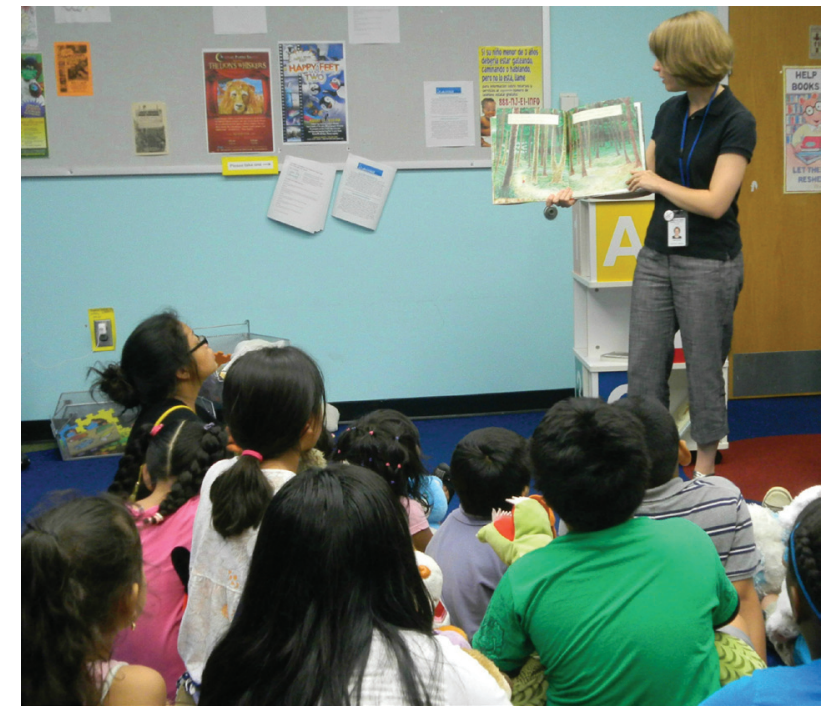

Because my Spanish was rusty, I dug out my old high school Spanish textbook and began to study. I took an online Spanishlanguage class, practicing a little bit every day. Within a short time, I felt more confident in my use of the language.

Now, more than a year later, I find myself again leading a storytime. I smile as a group of eager fouryear-olds makes its way to the story room. I open the first book, Under My Hood I Have a Hat, and point to the girl on the page. "What does she wear on her feet?"

“Zapatos!” is the joyous response.

"Yes, that's right," I say. "Zapatos, or shoes, keep your feet warm."

While I am no master of the Spanish language, I am learning more every day to connect with my patrons. I know these children are learning from me-about the library, developing a love of reading, gaining exposure to English-but the truth is, I am learning just as much from them.

Amanda Spino is a Senior Librarian and Branch Manager of the Island Heights Branch of the Ocean County Library in New Jersey. She was formerly a Youth Services Librarian at the Lakewood Branch and Member at Large for the New Jersey Library Association's Children's Services Section Executive Board.

Got a great, lighthearted essay? A funny story about children and libraries? Books and babies? Pets and picture books? A not-so-serious look at the world of children's librarianship? Send your Last Word to Sharon Verbeten at CALeditor@yahoo.com. 